\title{
A drug utilization study of antiepileptic drugs uses in a tertiary care teaching hospital of India
}

\author{
Soumitra Mandal $^{1 *}$, Aruna Donepudi ${ }^{1}$, Jabeen Shaik Afshan ${ }^{2}$, Suryaprabha Turaga $^{2}$
}

\author{
${ }^{1}$ Department of Clinical Pharmacology and Therapeutics, ${ }^{2}$ Department of Neurology, Nizam's Institute of Medical \\ Science, Hyderabad, Telangana, India
}

Received: 17 September 2021

Revised: 12 October 2021

Accepted: 13 October 2021

\section{*Correspondence:}

Dr. Soumitra Mandal,

Email: Soumitra.habul@gmail.com

Copyright: $\odot$ the author(s), publisher and licensee Medip Academy. This is an open-access article distributed under the terms of the Creative Commons Attribution Non-Commercial License, which permits unrestricted non-commercial use, distribution, and reproduction in any medium, provided the original work is properly cited.

\begin{abstract}
Background: Epilepsy is a disorder characterized by repeated seizures due to the disorder of the neurons. Epilepsy needs life-long medical therapy. It is managed by polytherapy. Drug utilization studies help to determine rational combinations of drug use in epilepsy. Aims and objectives of the study were to analyses the drug utilization pattern of anti-epileptics and common types of epileptic seizures and to determine the safety of antiepileptic drugs (AEDs).

Methods: It was a prospective, cross-sectional, observational study. Patients attending neurology epilepsy OPD with $\mathrm{h} / \mathrm{o}$ seizures and taking at least one antiepileptic were recruited. Data was collected by taking demographic details including brief history of disease, clinical examination and reviewing OPD prescription. Details were recorded in case record form.

Results: We recruited 102 participants (57 male and 45 females) of mean age $29.68 \pm 10.52$. Mean age of onset of epilepsy was $18.9 \pm 10.5$ years. Among them $77(75.4 \%)$ were diagnosed as generalized tonic clonic seizures and 18 $(17.6 \%)$ were diagnosed as focal seizures. Monotherapy was given in $31(30.3 \%)$ patients while polytherapy was given in $71(69.7 \%)$ patients. Valproic acid was most commonly used monotherapy (12 patients). No fixed drug combinations were used. Clobazam in $55(53.9 \%)$ patients and valproic acid in $53(51.9 \%)$ patients were prescribed. The other AEDs prescribed were lamotrigine, oxcarbazepine, carbamazepine, lacosamide, zincosamide, perampanel, and phenytoin. All antiepileptics were prescribed in brand name. The prescribed daily dose (PDD) was less than defined daily dose (DDD) as per anatomical therapeutic chemical (ATC) classification. Two adverse effects were reported during study period. They were mood change and blurring of vision in two different patients.

Conclusions: The PDD was less than DDD as per ATC classification. Awareness should be created among neurologists to prescribe more generic drugs because of their cost effectiveness. Studies are needed with larger sample size to analyze the drug utilization patterns which helps in the planning of reduction of expenditure for the patient without compromising efficacy.
\end{abstract}

Keywords: Epilepsy, Drug utilization, Antiepileptics

\section{INTRODUCTION}

Drug utilization research was defined by WHO in 1977 as "the marketing, distribution, prescription, and use of drugs in a society" with special emphasis on the resulting medical, social and economic consequences. The study of drug utilization is an evolving field. The importance of drug utilization studies has been increasing due to heightened marketing of new drugs, widespread variations in the prescribing pattern of drugs and its consumption, increasing concerns about late onset adverse effects and the concern with respect to drug costs. ${ }^{1}$ Epilepsy is a disease of the brain defined by any of the following conditions: ${ }^{2}$ 1) At least two unprovoked (or reflex) seizures 
occurring > 24 hours apart, 2) One unprovoked (or reflex) seizure and a probability of further seizures similar to the general recurrence risk (at least 60\%) after two unprovoked seizures, occurring over the next 10 years 3 . Diagnosis of an epilepsy syndrome.

Epilepsy is a common, chronic neurological disease which requires long term treatment and poses a heavy burden on health-care system. Pharmacotherapy of epilepsy only provides symptomatic relief. The AEDs were also used for various other conditions like prophylaxis of manic disorder and neuropathic pain. ${ }^{3}$

It is recommended that the epidemiologic study of epilepsy should follow the guidelines formed by the international league against epilepsy (ILAE) commission of epidemiology and prognosis. ${ }^{4}$ The type of epilepsy determines the most appropriate choice of drug therapy for a patient with seizure. Single drug therapy is the usual treatment recommended initially as:

It has fewer drug interactions and side effects, cost effective, better tolerability, better medication compliance, and good quality of life. Polytherapy is needed only for patients with multiple seizure types or refractory diseases. Major expenditure related to the treatment lies with the purchase of second-generation AEDs, which are more expensive compared to the first-generation agents. Drugs such as gabapentin, lamotrigine, vigabatrin, topiramate, tiagabine, and zonisamide are the newer ones and currently used as add-on or alternative therapy. They have lesser adverse effects. $^{5-7}$

In this context, and considering that there are few studies on antiepileptic use in southern India, we aimed to determine the utilization pattern of these drugs in a tertiary hospital. Hence this study was planned to assess the number of AEDs used per prescription, and the prescriptions are as per standard guidelines or not.

\section{METHODS}

The present study was a prospective, cross sectional, observational study. It was conducted in the department of clinical pharmacology and therapeutics and department of neurology, NIMS, after NIEC approval. (45 ${ }^{\text {th }}$ ESGS no. 936/2019). Study duration was of 3 months (December 2019 to march 2020). Inclusion criteria were patients having history of seizures, aged between 18 to 65 years of either gender and prescribed at least one epileptic drug. Exclusion criteria were seizures associated with acute causes like paralytic stroke, trauma and patients having status epilepticus.

Written informed consent was taken from all the study participants prior to enrolment into the study. All the OPD prescriptions were screened. Data was collected by taking brief medical and treatment history, clinical examination. Type of epilepsy, AEDs prescribed, dose, duration, any fixed dose combinations (FDCs), generic and branded drugs of all AEDs were recorded in case record form. Study outcomes were common types of epilepsy, average age of on-set of seizures, Number of antiepileptics prescribed per patient, most commonly prescribed AEDs, to compare PDD with DDD.

\section{Statistical analysis}

Data was presented as mean \pm SD for continuous variables, proportions for nominal variables. Statistical analysis was performed using Microsoft excel software for data stratification and analysis.

\section{RESULTS}

One hundred and two patients were enrolled into the study. Enrolment of patients was stopped due to sudden outbreak of COVID-19 pandemic. Mean age of the participants was $29.68 \pm 10.52$ years. Demographic characteristics were shown in Table 1.

Table 1: Demographic characteristics, $(n=102)$.

\begin{tabular}{|l|l|}
\hline Patients' characteristics & Mean \pm SD \\
\hline Age (years) & $29.68 \pm 10.52$ \\
\hline Gender $(\%)$ & $57(55.88)$ \\
\hline Male & $45(44.11)$ \\
\hline Female & $23.09 \pm 3.07$ \\
\hline BMI $\left(\mathbf{k g} / \mathbf{m}^{2}\right)$ & 2.4 \\
\hline $\begin{array}{l}\text { Average number of antiepileptics } \\
\text { per prescription }\end{array}$ & Nil \\
\hline $\begin{array}{l}\text { Average no. antiepileptics as } \\
\text { generics }\end{array}$ & Nil \\
\hline Number of FDC & \\
\hline
\end{tabular}

The average age of on-set of seizures in participants was $18.9 \pm 10.5$ year. The most common types of seizures observed were generalized tonic clonic seizures $(75.49 \%)$ and focal seizures $(17.64 \%)$. Various types of epilepsies observed were denoted in Table 2.

Table 2: Types of seizures observed, $(n=102)$.

\begin{tabular}{|l|l|}
\hline $\begin{array}{l}\text { Types of seizures } \\
\text { seizures }\end{array}$ & Observed $(\%)$ \\
\hline Focal seizures & $77(75.49)$ \\
\hline Myoclonic seizures & $18(17.64)$ \\
\hline Absence seizures & $2(1.96)$ \\
\hline Clonic seizures & $2(1.96)$ \\
\hline $\begin{array}{l}\text { Secondary generalized } \\
\text { seizure }\end{array}$ & $1(0.98)$ \\
\hline Non classified & $1(0.98)$ \\
\hline
\end{tabular}

More than 3 drugs were prescribed for most of patients (49.01\%). Mono-therapy constituted $30.39 \%$ and Dual drug therapy $20.58 \%$. Actual number of antiepileptics prescribed per patient were depicted in Figure 1. 


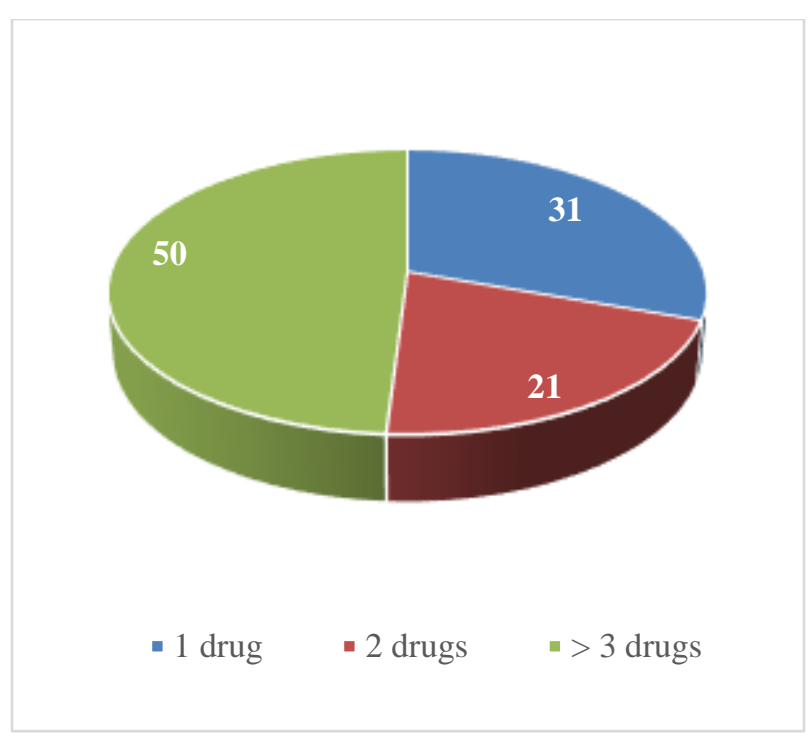

Figure 1: Number of antiepileptics prescribed per patient.

The number of patients prescribed monotherapy were 31 out of 102. Among the patients prescribed monotherapy, Valproic acid was the most commonly prescribed drug (12 patients) followed by oxcarbazepine 7 , levetiracetam 7 , phenytoin 4, lamotrigine 1 (Figure 2).

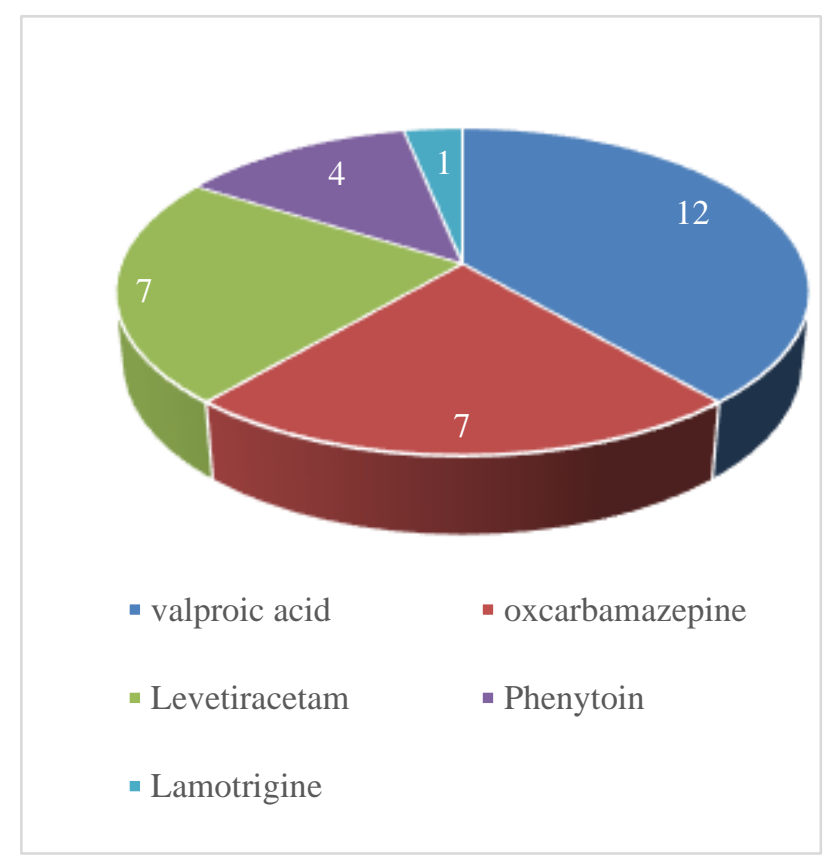

Figure 2: Antiepileptic monotherapy.

None of the patients were prescribed generic drugs and FDCs. The doses of AEDs prescribed in this study were less than that of DDD of each drug except for brivaracetam and phenobarbital (Table 3).

Two adverse effects were reported during the study period. They were mood changes due to levetiracetam and blurring of vision in phenytoin therapy patients.
Table 3: Antiepileptics utilization pattern.

\begin{tabular}{|ll|ll|}
\hline Drugs & Nomenclature & $\begin{array}{l}\text { DDD } \\
\text { as per } \\
\text { ATC }^{8} \\
(\mathbf{g m})\end{array}$ & $\begin{array}{l}\text { PDD } \\
(\mathrm{gm})\end{array}$ \\
\hline Lamotrigine & N03AX09 & 0.3 & 0.153 \\
\hline Clobazam & N05BA09 & $20 \mathrm{mg}$ & $\begin{array}{l}9.37 \\
\mathrm{mg}\end{array}$ \\
\hline Perampane & N03AX22 & $8 \mathrm{mg}$ & $\begin{array}{l}3.56 \\
\mathrm{mg}\end{array}$ \\
\hline Valproic acid & N03AG01 & 1.5 & 0.471 \\
\hline Zonisamide & N03AX15 & 0.2 & 0.192 \\
\hline Carbamazepine & N03AF01 & 1 & 0.513 \\
\hline Phenytoin & N03AB02 & 0.3 & 0.287 \\
\hline Oxcarbazepine & N03AF02 & 1 & 0.817 \\
\hline Lacosamide & N03AX18 & 0.3 & 0.174 \\
\hline Levetiracetam & N03AX14 & 1.5 & 0.887 \\
\hline Brivaracetam & N03AX23 & 0.1 & 0.166 \\
\hline Phenobarbital & N03AA02 & 0.1 & 0.15 \\
\hline
\end{tabular}

\section{DISCUSSION}

In the present study average age of onset of seizures was found to be $18.9 \pm 10.5$ years, which was similar from finding of other such study. ${ }^{5}$ In our study, the epilepsy is most prevalent in males compared to females, which is consistent with studies conducted by Arulkumarana et al and Patel et al. ${ }^{9,10}$ Most common type of seizure noted was GTCS, which is consistent with the findings of other studies. Average number of anti-epileptics per prescription was 2.42 in our study, which is higher when compared to study by Arunkumaran et al. ${ }^{9}$

It was found in our study that none of the AEDs prescribed by generic names, in spite of the fact that generic drugs are cost effective when compared to brand ones. The results of our study highlight significant unawareness of the process of generic substitution among both patients and neurologists and reveal a general level of discomfort among neurologists to prescribe generic AEDs. Our results were consistent with one survey. ${ }^{11}$ For those anti-epileptics with narrow therapeutic index, the value of sticking to the brand name is also crucial because switching from one brand to a generic drug might not be therapeutically comparable to the branded drug, which may put patients at risk of breakthrough seizures or other adverse events. ${ }^{12,13}$

We found that valproic acid was the most commonly prescribed broad spectrum antiepileptic drug. Valproic acid was found to be the most commonly used drug in other studies also. Some studies reported phenytoin as one of the most commonly used drugs due to its low cost and fair seizure control rate which allows its large-scale use. ${ }^{6,7}$ In contrast, our study reported lower use of phenytoin due to its pharmacokinetics and side effect profile.

We have found that $30.39 \%$ patients were prescribed monotherapy of antiepileptic drug. Our finding is in 
contrast to a study conducted by Patel et al which reported $70.6 \%$ patients were prescribed monotherapy. ${ }^{10}$ The difference may be due to the inclusion of patients who were prescribed anti-epileptic drugs for non-epileptic conditions. In another study monotherapy was given in $57.89 \%$ of patients. But the sample size was less $(n=38)$ in this study. ${ }^{12}$ It was also found that $49.01 \%$ of patients were prescribed $>3$ drugs, which is higher when compared to other studies. The literature says that chances of drug-drug interactions were increased with polytherapy. The reason for higher percentage of our patients on polytherapy, is due to higher number of drug resistant epilepsies who were referred from other centres for further management.

DDD greater than PDD was found in all AEDs except brivaracetam and phenobarbital probably to avoid the side effects. Newer ones perampanel, topiramate and lamotrigine were used to a very less extent. This may be due to the fact that newer antiepileptics are costly as compared to conventional ones. Several factors affect the selection and acceptance of anti-epileptic drugs by doctors, including the age, patient gender, weighting of effectiveness against possible ADRs, epilepsy syndromes and type, comorbid conditions, peer advice, familiarity with treatment of AEDs, and healthcare system prevailing in a specific area. Drug utilization studies help to assess prevailing health care practices, so that lacunae in the system can be found out and strategies can be planned to rectify them.

\section{Limitations}

The limitations of this study were smaller sample size and shorter study period.

\section{CONCLUSION}

The PDD was less than DDD as per ATC classification. Awareness should be created among neurologists to prescribe more generic drugs because of their cost effectiveness. Further studies with larger sample size are needed to help the physicians to administer cost effective drugs to the patient and to initiate strategies for reducing the irrational prescribing of AEDs and help the government to frame policies for medical reimbursement programs.

\section{ACKNOWLEDGEMENTS}

Author would like to thanks neurology department staff for their support and encouragement in carrying out this work.

\author{
Funding: No funding sources \\ Conflict of interest: None declared \\ Ethical approval: The study was approved by the \\ Institutional Ethics Committee
}

\section{REFERENCES}

1. Introduction to Drug Utilization Research. Oslo, Norway. WHO. 2003:1-73. Available at: https://apps. who.int/iris/handle/10665/42627. Accessed on 3 June 2021.

2. Fisher RS, Acevedo C, Arzimanoglou A, Bogacz A, Cross JH, Elger CE. ILAE official report: a Practical clinical definition of epilepsy. Epilepsia. 2014;55(4):475

3. Schachter SC. Current evidence indicates that antiepileptic drugs are anti-ictal, not antiepileptic. Epilepsy Res. 2002;50(1-2):67-70.

4. Shorvon SD. The etiologic classification of epilepsy. Epilepsia. 1997;38:614-8.

5. Badwaik RT, Mahajan HM, Borkar AS, Honrao R, Chopade SS. A Drug Utilization Study of Antiepileptic Drugs Use in a Tertiary Care Hospital of Central India. J Cont Med A Dent. 2015;3(2):33-8.

6. Machado-Alba J, Calvo-Torres L, García-Betancur S, Aguirre-Novoa A, Bañol-Giraldo A. Drug utilisation study in patients receiving antiepileptic drugs in Colombia. Neurología. 2016;31(2):89-96.

7. Newale S, Bachani DS. Demographic characteristics of epilepsy patients and antiepileptic drug utilization in adult patients: Results of a cross-sectional survey. Neurol India. 2016;64:1180-6.

8. WHO Collaborating Centre for Drug Statistics Methodology. ATC/DDD Index; 2019. Available at: https://www.whocc.no/atc_ddd_index/. Accessed on 2020, Oct 23.

9. Arulkumaran KS, Palanisamy S, Rajasekaran A. A study on drug use evaluation of anti-epileptics at a multispecialty tertiary care teaching hospital. Int $\mathbf{J}$ PharmTech Res. 2009;1(4):1541-7.

10. Patel PM, Shah AM, Gajjar BM. Drug utilization pattern of antiepileptic drugs in a tertiary care teaching rural hospital. Natl J Physiol Pharm Pharmacol. 2016;6(5):458-63.

11. Guberman A, Corman C. Generic substitution for brand name antiepileptic drugs: A survey. Can J Neurol Sci. 2000;27(1):37-43.

12. Vettikkadan AR, Jith A, Krishnaveni K, Sambath Kumar R. Study of utilization pattern and drug interactions of anti-epileptic drugs in a private hospital. Asian J Pharm Clin Res. 2014;7(5):164-6.

13. Antiepileptic drugs: The drawbacks of generic substitution. Lancet Neurol. 2011;9(3):227.

Cite this article as: Mandal S, Donepudi A, Afshan JS, Turaga S. A drug utilization study of antiepileptic drugs uses in a tertiary care teaching hospital of India. Int J Basic Clin Pharmacol 2021;10:1293-6. 